\title{
Repeated Treatment for Macular Edema in Vein Occlusion by Intravitreal Implant of Dexamethasone
}

\author{
Frederic Matonti ${ }^{a, b}$ Louis Hoffart ${ }^{b, c}$ \\ Christophe Baeteman $^{c}$ Danièle Denis ${ }^{a}$ \\ Ophthalmology Departments at ${ }^{\mathrm{a}}$ Hôpital Nord and ${ }^{\mathrm{b}} \mathrm{Hôpital}$ La Timone, and \\ 'Institut de Neurosciences de la Timone, Aix-Marseille University, \\ Marseille, France
}

\section{Key Words}

Macular edema - Vein occlusion - Intravitreal implant - Dexamethasone - Ranibizumab . Optical coherence tomography $\cdot \mathrm{Ozurdex}^{\circledast}$

\begin{abstract}
Background: Macular edema (ME) treatment has benefited from the recent intravitreal pharmacotherapy development of an intravitreal implant of dexamethasone (Ozurdex ${ }^{\circledR}$, Allergan, Irvine, Calif., USA). However, its efficiency has never been illustrated beyond 3 injections.
\end{abstract}

Case Presentation: We report the case of a 75-year-old woman with inferior branch vein occlusion, who, after laser photocoagulation treatment and recurrence after intravitreal injection of triamcinolone, benefited from 4 injections of Ozurdex. Her macular thickness and visual acuity (VA) progression were assessed for 17 months.

Conclusions: This case report highlights the quick efficiency of Ozurdex on VA and ME with good reproducibility and tolerance, and without tachyphylaxis phenomenon. This is the first illustrated description of 4 consecutive injections for ME induced secondary to retinal vein occlusion.

\section{Introduction}

Intravitreal pharmacotherapy for macular edema (ME) induced by retinal vein occlusion (RVO) has benefited from the recent development of a new treatment: intravitreal implant of dexamethasone (DII) (Ozurdex ${ }^{\circledR}$, Allergan, Irvine, Calif., USA), and from an extension of the indications of the marketing authorization of ranibizumab 
(Lucentis ${ }^{\circledR}$, Novartis Europharm Ltd., Basel, Switzerland) [1]. The use of these products has effectively improved not only the anatomical aspect of the retina by reducing the macular thickness and even in the best cases allowing the recovery of a normal foveal profile, but chiefly it has improved patients' vision quickly and sustainably. However, this all depends on repeated intravitreal injections (IVT).

In the case of ranibizumab, the mean number of injections is 8.4 per year according to the HORIZON study [2]; however, for Ozurdex it is 2 injections per year [3, 4], and more than 2 or 3 consecutive injections are rarely reported in the reference series $[3,4]$.

\section{Case Report}

We report the case of a 75-year-old woman with inferior branch vein occlusion, with refractory ME after laser photocoagulation treatment and recurrence after IVT of $4 \mathrm{mg}(0.1 \mathrm{ml})$ triamcinolone (fig. $\underline{1 A}$, a). Fluorescein angiography (FA) showed an inferior branch vein occlusion, with a moderate inferior ME with macular mild capillary nonperfusion (fig. 1A).

She underwent a 0.7 -mg DII in the right eye 1 year after IVT. Imaging by optical coherence tomography (OCT) was performed before (fig. 1a) and 1 month after (fig. 1b) the injection. It revealed a normalization of the foveal profile and resolution of cystic spaces correlated with an improvement of visual acuity (VA) from 20/120 to 20/50. After 5 months, ME reappeared (fig. 1c) and VA was altered (20/80). A second injection was performed with an impressive improvement after only 1 day, on anatomy (fig. 1d) and VA (20/40). On fundus photography performed after the second procedure, the intravitreal implant was clearly visible just behind the lens (fig. 1B). Despite this position, surprisingly, the patient was not symptomatic.

After 4.5 months, more moderate ME reappeared (fig. 1e) and VA decreased (20/60). A third injection was given and led to a transient improvement in vision (20/40), with progressive opacification of the lens but with a good anatomical result (fig. 1f). During follow-up, a recurrence of ME (fig. 1g) at 4.5 months led to a fourth injection with an identical effect on foveal anatomy (fig. 1h), but with a less important benefit on vision $(20 / 50)$ due to the cataract progression.

The cataract will be operated when the ME has totally and definitively vanished, or treated with a new DII if the opacification prevents any correct fundus visualization or if it generates a more important VA decrease. The last FA was not contributive, with no changes compared to the first one and was of poor quality due to the cataract. During follow-up, the intraocular pressure was between 14 and $17 \mathrm{~mm} \mathrm{Hg}$, with no pressure spike or need for pharmacological treatment.

\section{Discussion}

Here we present the first illustrated description of 4 consecutive injections for ME induced secondary to RVO. This case report highlights the quick efficiency [5] of Ozurdex on VA and ME with good reproducibility and tolerance, and without tachyphylaxis phenomenon. DII might be an effective treatment option in ME secondary to RVO even after the failure of laser treatment and preliminary triamcinolone treatment. So, this treatment could also be proposed as second-line treatment following laser treatment failure or after triamcinolone treatment.

It is important to note that even after 2 years of follow-up it is still possible to benefit from effective treatment with a low number of injections (4 in 17 months now, without recurrence); however, this comes at the expense of an increase of lens 
opacification and a risk of ocular hypertension, compared to treatment with ranibizumab.

\section{Disclosure Statement}

The authors have no financial disclosure or conflicts of interest, direct or indirect, to declare, and they have full access to all data in the study.
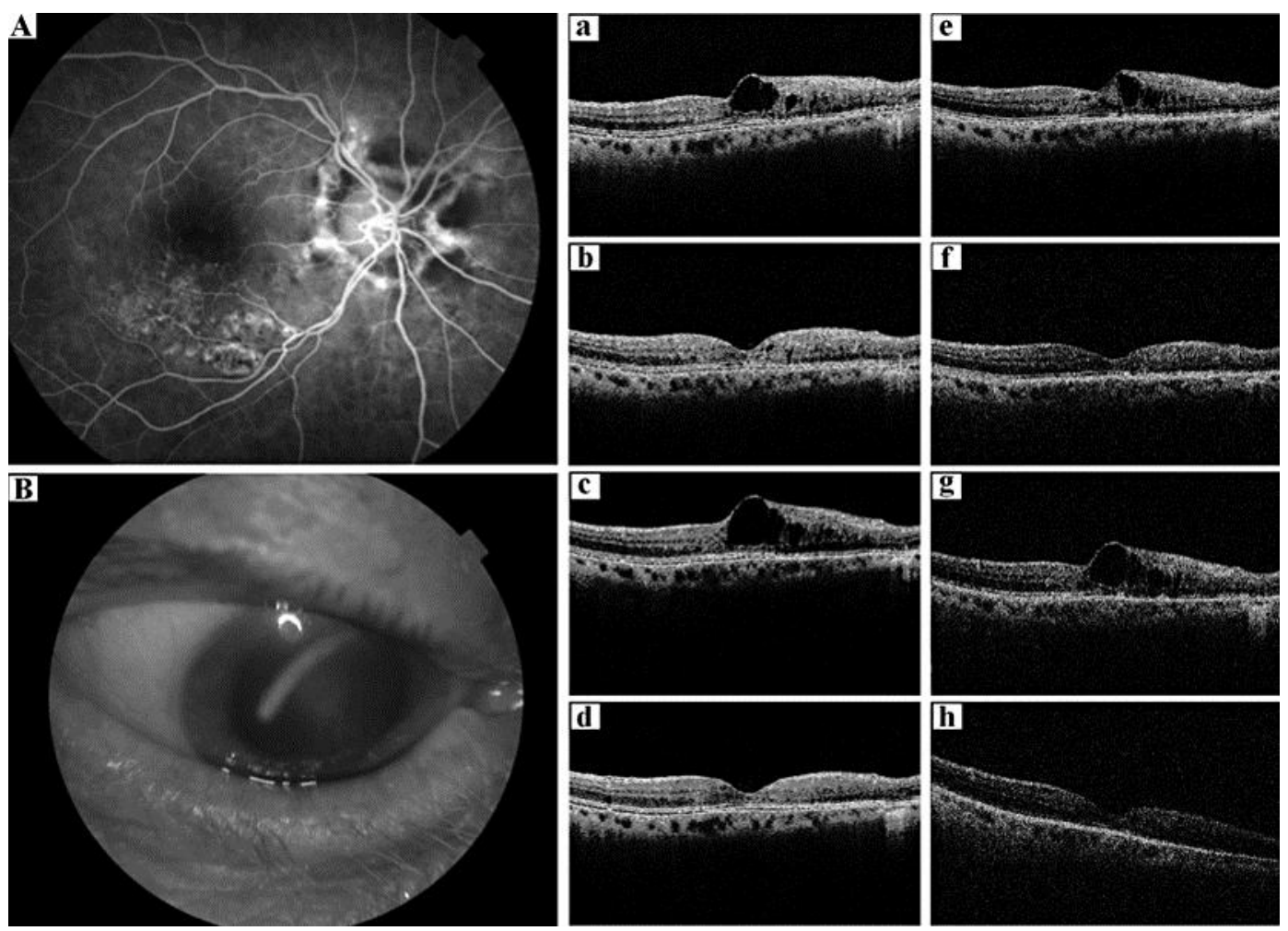

Fig. 1. FA, slit lamp and macular OCT. A FA shows inferior ME and mild ischemia secondary to inferior temporal vein occlusion with laser scars in the macular area. B Slit lamp examination shows the intravitreal implant just behind the lens with mild cortical cataract. $\mathbf{a}-\mathbf{h}$ Macular OCT vertical scans. a First exam 3 months after IVT of triamcinolone, cystoids ME on the inferior part of the macula. b 1 month after the first DII with a huge decrease of ME. Persistence of 2 microcysts. c Exam 5 months after the first DII with recurrent ME. $\mathbf{d}$ OCT 1 day after the second DII with normalization of the foveal profile. e Recurrence of mild ME 4.5 months after the second DII. f OCT 1 month after the third DII with disappearance of ME but signal deterioration of OCT due to lens opacification. $g$ Exam 4.5 months after the third DII with recurrent ME. $\mathbf{h}$ Vanishing of ME, but increase of signal deterioration explaining the bad quality of the examination. 


\section{References}

1 Hahn P, Fekrat S: Best practices for treatment of retinal vein occlusion. Curr Opin Ophthalmol 2012;23:175-181.

-2 Heier JS, Campochiaro PA, Yau L, Li Z, Saroj N, Rubio RG, Lai P: Ranibizumab for macular edema due to retinal vein occlusions: long-term follow-up in the HORIZON trial. Ophthalmology 2012;119:802-809.

-3 Haller JA, Bandello F, Belfort R Jr, Blumenkranz MS, Gillies M, Heier J, Loewenstein A, Yoon YH, Jacques ML, Jiao J, Li XY, Whitcup SM; OZURDEX GENEVA Study Group: Randomized, sham-controlled trial of dexamethasone intravitreal implant in patients with macular edema due to retinal vein occlusion. Ophthalmology 2010;117:1134-1146.

-4 Haller JA, Bandello F, Belfort R Jr, Blumenkranz MS, Gillies M, Heier J, Loewenstein A, Yoon YH, Jiao J, Li XY, Whitcup SM; Ozurdex GENEVA Study Group, Li J: Dexamethasone intravitreal implant in patients with macular edema related to branch or central retinal vein occlusion twelve-month study results. Ophthalmology 2011;118:2453-2460.

-5 Meyer LM, Schönfeld CL: Fast resolution of recurrent pronounced macular edema following intravitreal injection of dexamethasone $0.7 \mathrm{mg}$. Case Report Ophthalmol 2011;2:246-250. 